\title{
Oculosympathetic paresis caused by foreign body perforation of pharyngeal wall
}

\author{
${ }^{1}$ Isaac Bazak, ${ }^{1}$ Ariel Miller and ${ }^{2}$ Nehama Uri \\ Departments of ${ }^{1}$ Neurology and ${ }^{2}$ Otolaryngology, Carmel Hospital, Haifa, Israel.
}

\begin{abstract}
Summary: Ingestion of a foreign body rarely produces symptoms. We report a patient who presented with oculosympathetic paresis. We believe this is a previously unrecorded manifestation of foreign body ingestion.
\end{abstract}

\section{Introduction}

Oculosympathetic paresis (Horner's syndrome) consists of miosis, narrowed palpebral fissure, varying degree of facial anhydrosis and occasional heterochromia of the congenital type. ${ }^{1,2}$

The syndrome results from an interruption of the sympathetic pathway at any point along its course from the hypothalamus to the orbit. We would like to report a unique case of oculosympathetic palsy due to foreign body ingestion.

\section{Case report}

A 13 year old girl had fever up to $38.5^{\circ} \mathrm{C}$ and transient sore throat for 2 months and was treated with antibiotics, until the family noticed ptosis of the left eyelid with ipsilateral miosis. The girl was referred to the hospital for evaluation of left Horner's syndrome.

Review of the child's old photographs revealed that palpebral fissures and pupils had been identical. The developmental milestones were normal and the child was otherwise fit and healthy. The patient denied any trauma, and there was no history of pica syndrome. Family history was non-contributory.

Both general and neurological examination were normal except for fever of $37.5^{\circ} \mathrm{C}$ with marked ptosis of left eyelid and left miosis (Figure 1). Palpebral fissure size: right $11 \mathrm{~mm}$ and left $7 \mathrm{~mm}$. There was no difference of iris colour between the two eyes (dark brown). The right pupil measured $6 \mathrm{~mm}$ in diameter and the left $3 \mathrm{~mm}$ in ordinary room illumination, there was increased anisocoria in dim light $(4.5 \mathrm{~mm})$, with obvious 'dilatation lag' at 5 seconds. ${ }^{3,4}$ The pupils, though unequal, reacted to light and the consensual and covergence reflexes were both preserved. No

Correspondence: I. Bazak, M.D.

Accepted: 3 February 1987 differences in colour or sweating between the two sides of the face or body were observed.,

Pharmacological pupillary testing revealed failure of the left pupil to dilate with $5 \%$ cocaine eyedrops.

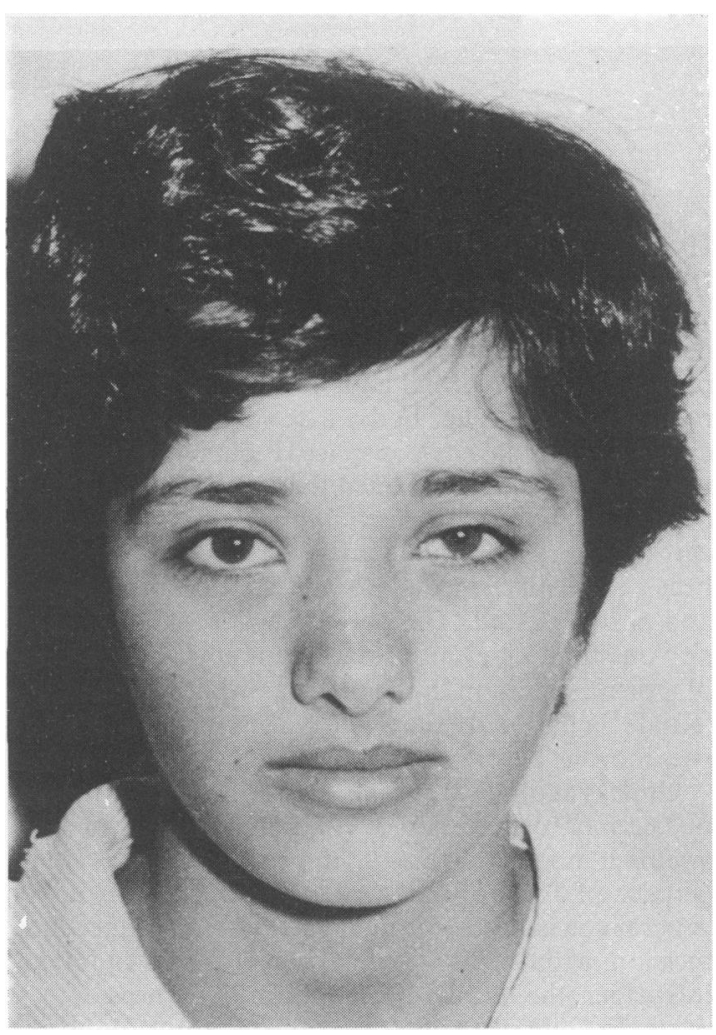

Figure 1 The patient on admission, with left eye oculosympathetic paresis.

(C) The Fellowship of Postgraduate Medicine, 1987 


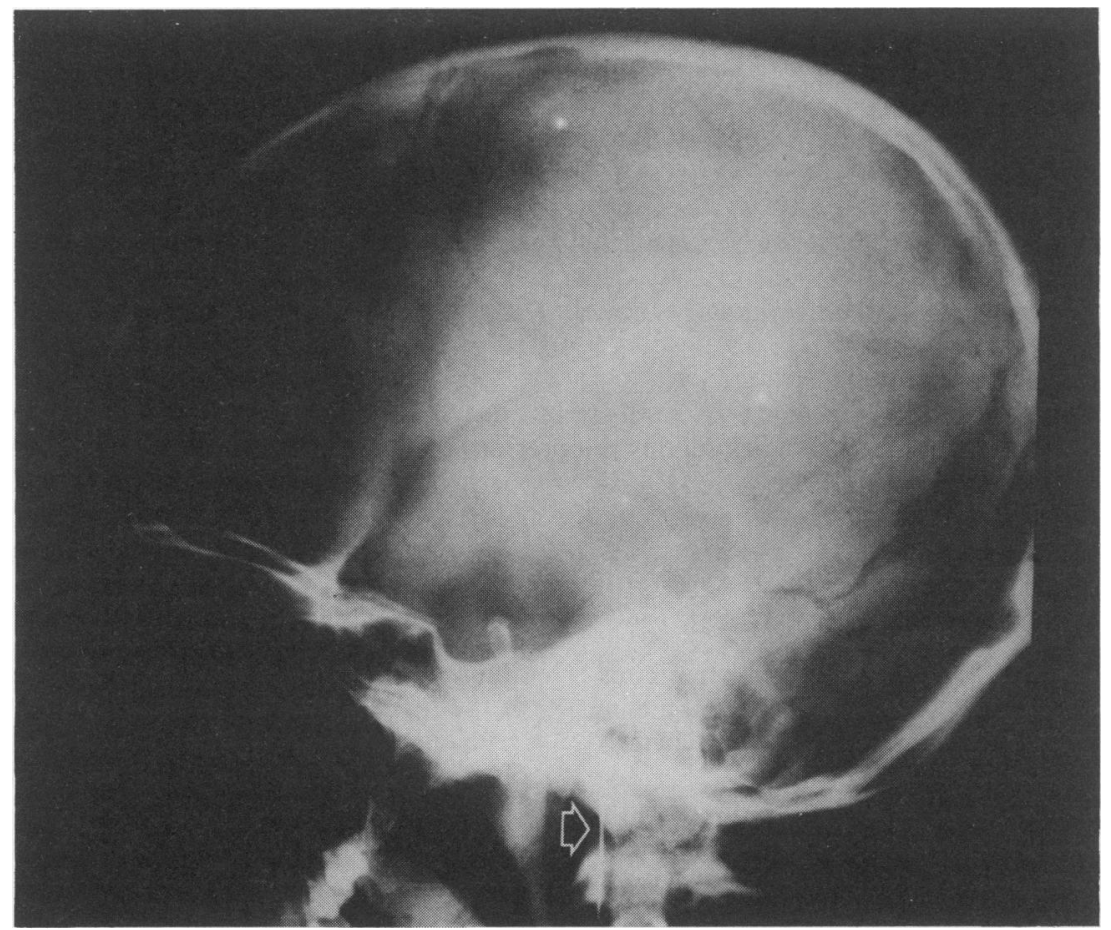

Figure 2 Swallowed foreign body in the retrostyloid space: plain lateral skull X-ray.

Hydroxyamphetamine $1 \%$ was not available for further pharmacological testing. ${ }^{\text {? }}$

Routine blood and urine analysis, electrocardiogram, electroencephalogram and chest radiography were within normal limits. Neck X-ray revealed a radio-opaque foreign body, a sewing needle, embedded at the left retrostyloid space (Figure 2). Computed tomographic scan confirmed these findings. The head of the needle was in the vicinity of the left internal carotid artery, internal jugular vein and vagus, and its other extremity, medial to the sternocleidomastoid and parotid gland. The parents when asked to recall any outstanding event told about a neglected episode of a prick sensation in the pharynx when the girl ate a 'Knafe', a national cake made of thin spaghetti dough, two months before she was referred for treatment.

Otolaryngological reexamination was normal with no sign of penetration wound in the pharynx, no swelling, no tenderness in the neck, and no enlargement of focal lymph nodes. At operation, under general anaesthesia, through a left lateral longitudinal incision, with the use of metal detector and an imageintensifier the needle was surgically removed in 2 parts. In spite of the fact that pus was not found the wound was drained for 3 days.

Post-operatively the patient made an uneventful recovery. The anisocoria seemed less marked $(2 \mathrm{~mm})$ 年 during the first postoperative week, with almosh complete recovery at the time of follow-up, 90 dayso after discharge.

\section{Discussion}

The diagnosis of oculosympathetic palsy was a clinica one but testing with cocaine $5 \%$ was done for confir mation of sympathetic denervation and to distinguish it from pseudo-Horner's syndrome., ${ }^{8,9}$

It is postulated that the foreign body perforated the pharynx and the Horner's syndrome could be due to haematoma, inflammation (with pressure and/or ischaemia), or direct trauma to the sympathetic chain It is also possible that ischaemia of the cervicaE. svmpathetic chain resulted from traumatic thrombosiss to the vasa nervorum.

In a large series ${ }^{8}$ the cause of Horner's syndrom织 was obscure in $40 \%$. Tumour infiltration, usuallyw accompanied by additional signs and symptoms, was the most commonly recognized cause, along witk trauma, irradiation or invasive procedures along the sympathetic chain. ${ }^{10,11}$ Oculosympathetic paralysis is ${ }^{\text {? }}$ also a prominent feature of Raeder's paratrigeminato 
neuralgia and may occur with cluster headache. In both syndromes the sympathetic fibres near the Gasserian ganglion are involved. ${ }^{12,13}$ It is suspected that local vascular aneurysm or thrombosis is a frequent but not often detected cause of Horner's syndrome. ${ }^{14,15}$

In children, Horner's syndrome with heterochromia may be congenital; an oculosympathetic palsy otherwise is suggestive of a malignant tumour. ${ }^{16,17}$

Ingestion of foreign bodies, a common occurrence, rarely produces symptoms. ${ }^{18}$ Perforation is more likely to occur in the oesophagus than in the rest of the

\section{References}

1. Waksh, F.B. \& Hoyt, W.F. In Clinical Neuroophthalmology. Williams \& Wilkins, Baltimore, 1969, pp 514521.

2. Smith, C.H. \& Beck, R.W. In Neurologic Clinics, Symposium on Neuro-Ophthalmology. W.B. Saunders, Philadelphia, 1983, pp870-874.

3. Pilley, S.F.J. \& Thompson, H.S. Pupillary dilatation lag in Horner's syndrome. Br J Ophthalmol 1975, 59: 731735.

4. Van Der Weill, H.L. \& Van Gijn, J. Horner's syndrome, criteria for oculosympathetic denervation. J Neurol Sci 1982, 56: 293-298.

5. Reeves, A.G. \& Posner, J.B. The ciliospinal response in man. Neurology 1969, 19: 1145-1152.

6. Morris, J.C.L., Lee, J. \& Lim, C.L. Facial sweating in Horner's syndrome. Brain 1984, 107: 751-758.

7. Van Der Weil, H.L. \& Van Gijn, J. Localization of Horner's syndrome, use and limitation of the hydroxyamphetamine test. J Neurol Sci 1983, 59: 229-235.

8. Maloney, W.F., Young, B.R. \& Moyer, N.J. Evaluation of the causes and accuracy of pharmacologic localization in Horner's syndrome. Am J Ophthalmol 1980, 90: 394 402.

9. Thompson, B.M. Corbet, J.J., Kline, L.B. \& Thompson, H.S. Pseudo-Horner's syndrome. Arch Neurol 1982, 39: $108-111$. gastrointestinal tract. ${ }^{19}$ The case described herein is to our knowledge the first published case report of oculosympathetic paresis following foreign body ingestion.

\section{Acknowledgement}

We thank Aharona Greenwald for preparation of the manuscript.

10. Giles, C.L. \& Henderson, J.M. Horner's syndrome, an analysis of 216 cases. Am J Ophthalmol 1958, 46: 289296.

11. Keasne, J.R. Oculosympathetic paresis. Analysis of $\mathbf{1 0 0}$ hospitalized patients. Arch Neurol 1979, 36: 13-15.

12. Raeder, J.G. 'Paratrigeminal' paralysis of oculopupillary sympathic. Brain 1947, 47: 119.

13. Riley, F.C. \& Moyer, N.J. Oculosympathetic paresis associated with cluster headache. Am J Ophthalmol 1977, 4: 763-768.

14. Sears, M.H., Keir, E.L. \& Chavis, R.M. Horner's syndrome caused by occlusion of the vascular supply to sympathetic ganglia. Am J Ophthalmol 1974, 5: 717-724.

15. Zisefein, J. Post ganglionic Horner's syndrome in carotid artery disease. Mount Sinai Med 1981, 5: 466-468.

16. Sauer, C. \& Levinson, M.W. Horner syndrome in childhood. Neurology 1976, 26: 216-220.

17. Weinstein, J.M., Zweifel, T.J. \& Thompson, H.S. Congenital Horner's syndrome. Arch Ophthalmol 1980, 98: 1074-1078.

18. Mandi, P. \& Ong, G.B. Foreign body in the oesophagus review of 2394 cases. Br J Surg 1978, 65: 5-9.

19. MaCanse, D.E., Kurchin, A. \& Hinshaw, J.R. Gastrointestinal foreign bodies. Am J Surg 1981, 142: 335-337. 